\title{
DEXTRAN/ASPIRIN VERSUS HEPARIN/DIHYDROERGOTAMINE IN PREVENTING THROMBOSIS AFTER HIP FRACTURES
}

\author{
M. PINI, E. SPADINI, L. CARluCCIO, C. GIOVANARDi, E. MAGNANI, U. UGOlOTTI, E. UGGERI
}

From Ospedale Maggiore, Parma

\begin{abstract}
In a randomised trial we compared the effects of two different antithrombotic regimens on the incidence of venographically established deep venous thrombosis (DVT) in 83 patients undergoing surgery for fracture of the femoral neck. Group A received dextran 40 peroperatively plus $0.5 \mathrm{~g}$ aspirin a day beginning before operation and continuing for 10 days after. Group B received heparin calcium 5000 iu subcutaneously plus dihydroergotamine (DHE) $0.5 \mathrm{mg}$ intramuscularly, given 8-hourly, beginning before operation and continuing for 10 days after.

Two patients in Group A and three in Group B developed proximal DVT, while the incidence of all DVT was $33 \%$ in Group $A$ and $29 \%$ in Group B, a difference which was not significant. Haemorrhagic complications were much more common in the dextran/aspirin group: the volume of drainage fluid, the number of patients transfused and quantity of blood transfused, and the drop in haemoglobin level were all significantly greater in Group A.

We conclude that the DHE/heparin regime is preferable to dextran/aspirin because it is safer and no less effective.
\end{abstract}

The studies of Borgström et al. (1965), Eskeland, Solheim and Skjörten (1966), Freeark. Bostwick and Fardin (1967), Culver et al. (1970), Hamilton et al. (1970) and Morris and Mitchell (1976) have shown that $40 \%$ to $68 \%$ of patients undergoing post-traumatic surgery of the hip develop deep venous thrombosis (DVT) and 5\% to $8 \%$ die because of pulmonary embolism if no antithrombotic prophylaxis is provided. Conventional lowdose heparin is inadequate in this situation (Myrvold et al. 1973; Morris and Mitchell 1977; Williams et al. 1978) and many alternative treatments have been tried, with variable success. A number of studies (Sagar et al. 1976; Kakkar et al. 1979; Schöndorf and Weber 1980: Morris and Hardy 1981) have demonstrated the efficacy of dihydroergotamine (DHE) associated with heparin in preventing DVT after elective hip surgery, and this drug combination has increasingly been used for this purpose, especially in Europe. Dextran also has been shown to be effective in reducing the incidence of DVT after elective and post-traumatic hip surgery (Johnsson,

M. Pini, MD. Deputy Head, Department of Medicine

E. Spadini. MD. Assistant

L. Carluccio. MD. Assistant

C. Giovanardi. MD. Assistant

E. Uggeri. MD. Head. Department of Anaesthesiology

U. Ugolotti, MD. Assistant. Department of Radiology

Ospedale Maggiore, Via Gramsci 14, 43100 Parma. Italy.

E. Magnani, MD, Assistant. Department of Orthopaedics University of Parma. Via Gramsci 14. 43100 Parma. Italy.

Requests for reprints should be sent to Dr M. Pini.

(. 1985 British Editorial Society of Bone and Joint Surgery $0301-620 \times 852068 \$ 2.00$
Bygdeman and Eliasson 1968: Ahlberg et al. 1968; Myhre and Holen 1969: Evarts and Feil 1971). It is considered by some authorities to be the prophylactic measure of choice for elective hip surgery (Hirsh, Genton and Hull 1981) but most orthopaedic surgeons are reluctant to use dextran after a fractured hip, because this usually occurs in elderly people who are more susceptible to the risk of heart failure precipitated by colloid-induced circulatory overload. Contradictory results have been obtained with aspirin in orthopaedic surgery, reports of efficacy (Harris et al. 1977; Hume et al. 1977) not having been confirmed by subsequent studies (Morris and Mitchell 1977; Stamatakis et al. 1978; Channon and Wiley 1979).

We thought it useful to evaluate the antithrombotic effectiveness of dextran associated with aspirin in hip fractures, reasoning that these two drugs could be synergistic, by virtue of their inhibitory effect on platelet adhesion and aggregation respectively, thus allowing the reduction of colloid administered without any loss of antithrombotic effect. This drug combination had already been used by Salvati and Lanchiewicz. (1976), but they relied on clinical diagnosis of postoperative DVT.

In our randomised trial, we compared the efficacy of dextran/aspirin in preventing venographically established DVT after post-traumatic surgery of the hip, with that of DHE/heparin, which is our current thromboprophylactic treatment in operations carrying a high risk of thrombosis. If equally effective and safe, the dextran/ aspirin combination would be preferable because it is cheaper and requires fewer injections. 


\section{PATIENTS AND METHODS}

Between February 1982 and September 1983 all patients admitted to the First Department of Orthopaedics, Ospedale Maggiore of Parma, after a fracture of the femoral neck were considered for the trial. Criteria for exclusion were:

1. Thrombocytopenia, severe anaemia, or abnormalities of coagulation.

2. Active peptic ulceration.

3. Severe liver or kidney disease.

4. Recent use of aspirin.

5. Known hypersensitivity to dextran, DHE or aspirin.

6. Heart failure.

7. Hypertension (diastolic pressure of $120 \mathrm{mmHg}$ or more).

8. Pathological fracture.

9. Multiple fractures.

10. Clinical thrombophlebitis on admission.

Before the trial, equal numbers of slips naming the alternative regimes were placed in envelopes, sealed, randomly mixed and numbered in sequence. If there were no grounds for exclusion, the patient was admitted to the trial and allocated to the assigned treatment by opening the next envelope.

Treatment schedules. All patients received routine physiotherapy throughout the study and were mobilised as rapidly as possible. Patients in Group A received $0.5 \mathrm{~g}$ of aspirin once daily beginning before operation and continuing for 10 days after; in addition, they received dextran $40,10 \%$ in saline, $500 \mathrm{ml}$ during the operation, $500 \mathrm{ml}$ about four hours after the operation, and $500 \mathrm{ml}$ on the next day. If, on the first evening, patients were unable to swallow the tablet of aspirin, it was dissolved in water. To check a possible dextran allergy, $20 \mathrm{ml}$ of the colloid were administered the day before operation, and the patient was monitored.

Patients allocated to Group B received both $5000 \mathrm{iu}$ of heparin calcium subcutaneously and $0.5 \mathrm{mg}$ of DHE intramuscularly 8-hourly, beginning before operation and continuing for 10 days after. Care was taken to avoid administration of non-steroid anti-inflammatory drugs or other antiplatelet agents. If thrombo-embolism was suspected, it was confirmed by objective testing, the prophylactic treatment was interrupted and therapeutic dosage of heparin begun.

The operation. Most trochanteric fractures were fixed with Ender's nails. Patients with intracapsular fractures underwent femoral head replacement by a Moore's endoprosthesis, or osteotomy plus osteosynthesis (see Table I). As a rule, patients were mobilised on the first postoperative day.

Monitoring and diagnosis. The patients were assessed clinically every day for symptoms or signs of venous thrombo-embolism, and venography was performed within 24 hours if there was any suspicion of DVT. If pulmonary embolism was suspected, an electrocardiogram, arterial blood gas analysis, chest radiographs, a lung perfusion scan and bilateral venography were performed. In all other patients bilateral venography was performed between the eighth and the tenth postoperative day. Cécile and Cordier's (1980) method was used and the venograms were interpreted by radiologists unaware of the group assignment. The presence of an intraluminal filling defect visible in all films was the criterion used to diagnose DVT.

Compliance was assessed daily by asking the patients and checking the medical and nursing records. Blood loss. The number of units of blood transfused, the volume of drainage loss and the presence and extent of wound haematomas were all noted. Haemoglobin levels were obtained before the operation, and on the second, fifth and tenth postoperative days. The drop in haemoglobin level was calculated by the difference between preoperative and predischarge levels.

Statistical analysis. Confidence limits were calculated to estimate the true incidence of proximal venous thrombosis and of all venous thromboses. The differences in this incidence between the two treatments were analysed with Fisher's exact test. The data on bleeding were analysed with the chi-squared test, using Yates' corrections, and Student's $t$-test for unpaired data.

\section{RESULTS}

Of the 110 consecutive patients admitted to hospital during the study period, $27(24 \%)$ were excluded from the trial (see under Patients and Methods). Of the remaining 83 patients, 42 were allocated to Group A (dextran plus aspirin) and 41 to Group B (heparin plus DHE). All patients except one had sustained a fracture in the 24 hours before admission to hospital. The relevant characteristics of the patients in the treatment groups were similar (Table I).

Two patients, both belonging to Group A, died during the study period. One was a 90 -year-old woman, who died on the third postoperative day, presumably because of heart failure; pulmonary embolism was ruled out by the autopsy findings. The other patient was a 91year-old woman who died on the sixth postoperative day because of cardiovascular collapse after developing intestinal obstruction; there was no clinical suspicion of pulmonary embolism; autopsy could not be performed.

Three other patients, all belonging to Group A, were withdrawn from the study: one had postoperative hypotension, one developed a cutaneous rash soon after operation, and in the third patient severe hypertension was found on the day after operation. Further dextran administration was considered hazardous in these three subjects.

Incidence of venous thrombosis. The incidence and distribution of deep venous thrombosis is shown in Table II. Twelve patients, four in Group A and eight in Group B, underwent venography of the operated limb only. Bilateral venography was obtained in all other patients. Fourteen of the 42 patients allocated to Group A 
Table I. Relevant characteristics of the two groups

\begin{tabular}{|c|c|c|}
\hline & Group A & Group B \\
\hline Number of patients & 42 & 41 \\
\hline \multicolumn{3}{|l|}{ Age (years) } \\
\hline$<60$ & 5 & 5 \\
\hline $60-69$ & 4 & 10 \\
\hline $70-79$ & 19 & 15 \\
\hline $80-89$ & 12 & 10 \\
\hline $90-99$ & 2 & 1 \\
\hline mean $\pm s v$ & $73.0 \pm 12.7$ & $72.8 \pm 13.0$ \\
\hline $\operatorname{Sex}(\mathrm{M}: \mathrm{F})$ & $12: 30$ & $8: 33$ \\
\hline \multicolumn{3}{|l|}{ Risk factors } \\
\hline Severe obesity ( $>20 \%$ overweight) & 8 & 5 \\
\hline Varicose veins & 4 & 6 \\
\hline Previous thrombophlebitis & 3 & 2 \\
\hline Previous stroke or myocardial infarction & 4 & $\overline{3}$ \\
\hline Diabetes & 4 & 3 \\
\hline Cancer & 0 & 1 \\
\hline \multicolumn{3}{|l|}{ Site of fracture } \\
\hline Trochanteric & 22 & 18 \\
\hline Intracapsular & 20 & 23 \\
\hline \multicolumn{3}{|l|}{ Type of operation } \\
\hline Ender nailing & 20 & 18 \\
\hline Nail and plate osteosynthesis & 2 & 0 \\
\hline Osteotomy plus osteosynthesis & 2 & 3 \\
\hline Endoprosthesis & 18 & 20 \\
\hline \multicolumn{3}{|l|}{ Anaesthesia } \\
\hline General & 19 & 21 \\
\hline Epidural & 23 & 20 \\
\hline Duration (minutes) mean \pm SD & $87.3 \pm 34.9$ & $87.5 \pm 28.4$ \\
\hline Delay to operation (days) mean $\pm \mathrm{SD}$ & $2.2 \pm 1.5$ & $3.5 \pm 2.8$ \\
\hline
\end{tabular}

(33.33\%; $95 \%$ confidence limits $19.57 \%-49.55 \%)$ and 12 of the 41 patients allocated to Group B $(29.27 \%$; confidence limits $16.13 \%-45.54 \%$ ) developed deep venous thrombosis. This difference is not significant $(P$ $=0.475$ ). Since the observed difference in the incidence of venous thrombosis between the two groups was $4.06 \%$ in favour of DHE/heparin, it is unlikely $(P<0.05)$ that a true difference in favour of DHE/heparin would be higher than $19.17 \%$, and the difference could be as much as $15.02 \%$ in favour of dextran/aspirin. There were only five instances of proximal DVT (that is, proximal to the

Table II. Incidence and distribution of thromboses (and related events)

\begin{tabular}{lcc} 
& $\begin{array}{l}\text { Group A } \\
(n=42)\end{array}$ & $\begin{array}{l}\text { Group B } \\
(n=41)\end{array}$ \\
All patients with DVT & 14 & 12 \\
Patients with proximal DVT & 2 & 3 \\
Pulmonary embolism (clinical evidence) & 0 & 1 \\
Deaths & 2 & 0 \\
Withdrawals & 3 & 0 \\
\hline Bilateral venography & 33 & 33 \\
DVT on side of fracture & 2 & 6 \\
DVT on opposite side & 4 & 2 \\
Bilateral DVT & 5 & 3
\end{tabular}

calf): two in Group A $(4.76 \% ; 95 \%$ confidence limits $0.058 \%-16.16 \%)$ and three in Group B $(7.32 \%$; confidence limits $1.54 \%-19.92 \%)$. This difference is not significant $(P=0.500)$. Since the difference was $2.56 \%$ in favour of dextran/aspirin, it is unlikely $(P<0.05)$ that a true difference in favour of dextran/aspirin would be higher than $10.12 \%$, and the difference could be as much as $7.89 \%$ in favour of $\mathrm{DHE} /$ heparin.

Of the 66 patients tested by bilateral venography, 22 developed DVT, of which eight were bilateral, eight on the operated side and six on the opposite side.

Delay in operation did not significantly affect the incidence of postoperative DVT. Sixty patients underwent operation within three days of admission, and 18 of them developed DVT $(30 \%)$; 18 were operated on after three days, and eight developed DVT $(44 \%)$.

Clinical evidence. Fourteen patients developed symptoms and/or signs suggesting DVT, but the diagnosis was confirmed by venography in only seven (three in Group $A$ and four in Group B). Lung scans were performed in two patients suspected of pulmonary embolism. In one of them there were no perfusion defects, and the diagnosis of pulmonary embolism was discarded. The other one, in Group B, showed a large perfusion defect, and bilateral venography demonstrated distal DVT of the non-operated leg.

Blood losses. The drop in haemoglobin levels, units of blood transfused, drainage losses and incidence of wound haematomas are reported in Table III. Transfusions were given to 29 patients in Group $A$ and to 19 in Group B $(P<0.01)$; they received 75 units and 39 units respectively $(P<0.01)$. Intra-operatively, 44 units were transfused to patients in Group A and 33 to Group B patients; while postoperatively, 31 and 6 units respectively were given $(P<0.001)$. Notwithstanding the higher amount of blood received, patients in Group A had a higher drop in haemoglobin level; the mean postoperative drainage loss was higher in Group A (see Table III). Platelet function. In a number of patients belonging to Group A, platelet function tests were performed on the first postoperative day and compared with basal values (data not reported). A $25 \%$ reduction of platelet adhesiveness, a slight reduction of platelet aggregation to collagen and a marked prolongation of bleeding time were observed which may explain the haemorrhagic sideeffects of the dextran/aspirin combination.

\section{DISCUSSION}

The results of this study suggest that the dextran/aspirin combination is as effective as the more commonly used DHE/heparin treatment in preventing deep venous thrombosis after post-traumatic hip surgery, but it causes more bleeding. The effect of the two treatments in the prevention of proximal venous thrombosis appears to be very similar, as the $95 \%$ confidence limits on the observed difference between the two groups is narrow (from $10.12 \%$ in favour of dextran/aspirin to $7.89 \%$ in 
Table III. Evaluation of blood loss and wound haematomas

\begin{tabular}{|c|c|c|c|}
\hline & Group A & Group B & $\begin{array}{l}\text { Statistical } \\
\text { significance }\end{array}$ \\
\hline Number of patients & 42 & 41 & \\
\hline \multicolumn{4}{|l|}{$\begin{array}{l}\text { Number of blood units } \\
\text { transfused }\end{array}$} \\
\hline Intraoperative & 44 & 33 & NS \\
\hline Postoperative & 31 & 6 & $P<0.001$ \\
\hline Total & 75 & 39 & $P<0.01$ \\
\hline Number of patients transfused & 29 & 19 & $P<0.05$ \\
\hline $\begin{array}{l}\text { Number of patients with } \\
\text { wound haematomas }\end{array}$ & 3 & 2 & NS \\
\hline \multicolumn{4}{|l|}{$\begin{array}{l}\text { Haemoglobin level }(\mathrm{g} / \mathrm{d} \mathrm{l})- \\
\text { mean } \pm \mathrm{S} \text { ) }\end{array}$} \\
\hline Pre-operative & $12.3 \pm 1.52$ & $12.5 \pm 1.43$ & \\
\hline 10th postoperative day & $9.8 \pm 1.42$ & $11.1 \pm 1.52$ & \\
\hline Drop & $2.5 \pm 1.38$ & $1.4 \pm 1.33$ & $P<0.001$ \\
\hline Postoperative drainage loss & $337.5 \pm 170$ & $260.7 \pm 175$ & $P<0.05$ \\
\hline
\end{tabular}

favour of DHE/heparin). Less firmly established, however, is the equivalence between the two treatments in preventing all venous thrombosis, as the $95 \%$ confidence limits on the observed difference between the two groups is wide (from $15.02 \%$ in favour of dextran/aspirin to $19.17 \%$ in favour of DHE/heparin).

The overall incidence of venographically proved DVT was quite high $(33.33 \%$ in Group A and $29.27 \%$ in Group B), but a very low incidence of proximal venous thrombosis was found in both groups $(4.76 \%$ versus $7.32 \%$ ), comparable to that recently reported by Leyvraz et al. (1983) with adjusted doses of heparin in elective hip surgery. The proximal/distal ratio observed in our study is in accordance with the findings of Channon and Wiley (1979) in post-traumatic surgery of the hip and in contrast with our experience in symptomatic DVT where the ratio was about 5:1 (Pini et al. 1984). Moreover, only one patient in Group A and two patients in Group B had proximal DVT without concurrent thrombi in the calf. These findings militate against the belief that a significant proportion of DVT occurring after hip surgery originates in the thigh, allegedly because of distortion of the common femoral vein at operation.

The results of our investigation also cast doubt on another current opinion (mainly based on studies employing radiofibrinogen scanning) that after hip surgery most thrombi develop in the operated limb. Of the 66 patients examined with bilateral venography, 22 developed DVT, of which eight were bilateral, eight on the operated side and six on the opposite side, a difference which is not significant. Culver et al. (1970) similarly reported a $40 \%$ incidence of DVT in 100 fractured limbs and a $50 \%$ incidence of DVT in the uninjured limb of 20 patients in whom bilateral venography had been per- formed. It therefore seems that unilateral venography may not be adequate in assessing the true frequency of DVT after hip surgery.

It is also worth noting that delay in operation did not significantly affect the incidence of postoperative DVT, which was $30 \%$ in the 60 patients who were operated on within three days of admission, and $44 \%$ in the 18 patients operated on later.

Conclusion. The conclusion that the dextran/aspirin combination causes more bleeding seems inescapable: except for wound haematomas, all indices of haemorrhagic side-effects examined confirm this finding. The volume of drainage loss, the number of patients transfused, the total number of units of blood transfused and the drop in haemoglobin level were all significantly higher in Group A patients than in Group B. The drop in haemoglobin level cannot be ascribed to the dextraninduced haemodilution, because predischarge determinations were obtained at least seven days after the last dose of dextran was administered.

Taking into account that two deaths occurred in Group A but none in Group B, and that three withdrawals, due to suspected side-effects of dextran, also occurred in Group A, we conclude that the antithrombotic regimen DHE/heparin is preferable to dextran/aspirin because it is safer and no less effective.

We are indebted to Dr Russell D. Hull and Dr Gary E. Raskob for reviewing the manuscript and for advice in performing statistical analysis.

\section{REFERENCES}

Ahlberg $\AA$, Nylander G, Robertson B, Cronberg S, Nilsson IM. Dextran in prophylaxis of thrombosis in fractures of the hip. Acta Chir Scand 1968; Suppl. 387:83-5.

Borgström S, Greitz T, Linden $W$ van der, Molin J, Rudics I. Anticoagulant prophylaxis of venous thrombosis in patients with fractured neck of the femur: a controlled clinical trial using venous phlebography. Acta Chir Scand 1965; 129:500-8.

Cécile J-P, Cordier R. Phlébographie des membres inférieurs. In: Pinet F. Chermet J, Amiel M, eds. Traité de radiodiagnostic. Paris: Masson, 1980:3:507-44

Channon GM, Wiley AM. Aspirin prophylaxis of venous thromboembolic disease following fracture of the upper femur. Can J Surg 1979:22(5):468-72.

Culver D, Crawford JS, Gardiner JH, Wiley AM. Venous thrombosis after fractures of the upper end of the femur: a study of incidence and site. J Bone Joint Surg [Br] 1970:52-B:61-9.

Eskeland G, Solheim K, Skjörten F. Anticoagulant prophylaxis, thromboembolism and mortality in elderly patients with hip fractures: a controlled clinical trial. Acta Chir Scand 1966;131: 16-29.

Evarts CM, Feil EJ. Prevention of thromboembolic disease after elective surgery of the hip. J Bone Joint Surg $[\mathrm{Am}]$ 1971: 53-A : $1271-80$.

Freeark RJ, Bostwick J, Fardin R. Posttraumatic venous thrombosis. Arch Surg 1967:95:567-75.

Hamilton HW, Crawford JS, Gardiner JH, Wiley AM. Venous thrombosis in patients with fracture of the upper end of the femur: a phlebographic study of the effect of prophylactic anticoagulation. J Bone Joint Surg [Br] 1970;52-B:268-89.

Harris WH, Salzman EW, Athanasoulis CA, Waltman AC, DeSanctis RW. Aspirin prophylaxis of venous thromboembolism after total hip replacement. N Engl J Med 1977:297: 1246-9.

Hirsh J, Genton E, Hull R. Venous thromboembolism. New York: Grune \& Stratton, $1981 ; 114$ 
DEXTRAN/ASPIRIN VERSUS HEPARIN/DHE IN PREVENTING THROMBOSIS AFTER HIP FRACTURES

309

Hume M, Bierbaum B, Kuriakose TX, Surprenant J. Prevention of postoperative thrombosis by aspirin. Am J Surg 1977;133:420-2.

Johnsson SR, Bygdeman S, Eliasson R. Effect of dextran on postoperative thrombosis. Act Chit Stand 1968; Suppl. 387:80-2.

Kakkar VV, Stamatakis JD, Bentley PG, Lawrence D, de Haas HA, Ward VP. Prophylaxis for postoperative deep vein thrombosis: synergistic effect of heparin and dihydroergotamine. $J A M A$ 1979:241:39-42.

Leyvraz PF, Richard J, Bachmann F, et al. Adjusted versus fixed-dose subcutaneous heparin in the prevention of deep-vein thrombosis after total hip replacement. $N$ Eng $J$ Med 1983;309:954-8.

Morris GK, Mitchell JRA. Warfarin sodium in prevention of deep venous thrombosis and pulmonary embolism in patients with fractured neck of femur. Lancet 1976;ii:869-72.

Morris GK, Mitchell JRA. Preventing venous thromboembolism in elderly patients with hip fractures: studies of low-dose heparin. dipyridamole, aspirin and flurbiprofen. Br Med J 1977:i:535-7.

Morris WT, Hardy AE. The effect of dihydroergotamine and heparin on the incidence of thromboembolic complications following total hip replacement: a randomized controlled clinical trial. Br J Surg 1981:68:301-3.

Myhre HO, Hole A. Tromboseprofylakse: dextran ellen warfarinnatrium? Word Med 1969;82:1534-8.
Myrvold HE, Person JE, Svensson B, Wallesten S, Vikterlof KJ. Prevention of thrombo-embolism with dextran 70 and heparin in patients with femoral neck fractures. Acta Choir Stand 1973; 139:609-16.

Pin M, Poi R, Poi T, Tagliaferri A, Dettori AG. Accuracy of straingauge plethysmography as a diagnostic test in clinically suspected deep venous thrombosis. Thrombi Res 1984:35: $149-57$.

Saga S, Nairn D, Stamatakis JD, et al. Efficacy of low-dose heparin in prevention of extensive deep-vein thrombosis in patients undergoing total-hip replacement. Lancet 1976;i:1151-4.

Salvati EA, Lanchiewicz $\mathbf{P}$. Thromboembolism following total hipreplacement arthroplasty: the efficacy of dextran-aspirin and dextran-warfarin in prophylaxis. $J$ Bone Joint Surg $[\mathrm{Am}]$ 1976; 58-A:921-5.

Schöndorf TH, Weber $U$. Prevention of deep vein thrombosis in orthopaedic surgery with the combination of low dose heparin plus either dihydroergotamine or dextran. Scald $J$ Haematol 1980:25 Suppl. 36:126-40.

Stamatakis JD, Kakkar VV, Lawrence D, Bentley PG, Nairn D, Ward V. Failure of aspirin to prevent postoperative deep vein thrombosis in patients undergoing total hip replacement. Br Med J 1978;i: 1031.

Williams JW, Eikman EA, Greenberg SH, et al. Failure of low dose heparin to prevent pulmonary embolism after hip surgery or above the knee amputation. Ann Surg 1978:188:468-74.

VOL. 67-B. No. 2, MARCH 1985 